\title{
Descubriendo la Salud y la Sexualidad en los Medios
}

\author{
Medios de Comunicación y Salud Pública. \\ La voz de los Adolescentes
}

Jesús Alejandro Hernández Ramírez*

En Noviembre de 1995 se estableció en Cuenca, Ecuador, un proyecto titulado "Proyecto COMSALUD - Latinoamérica", que se desarrolló en una reunión de la Federación Latinoamericana de Facultades de Comunicación Social (FELAFACS), y fue patrocinado por la Organización Panamericana de la Salud (OPS), entre otras instituciones. La intención principal del proyecto fue contribuir de manera significativa, equitativa y sostenible al desarrollo de la salud. Posteriormente se realizó un multi-estudio enfocado a la salud, $1 @ s$ adolescentes y los medios de comunicación en Latinoamérica llamado 'La Voz de los Adolescentes'- en los países de Colombia, Argentina, República Dominicana, Ecuador, El Salvador, Guatemala, Honduras, Paraguay, Perú, Nicaragua, Venezuela y México.

En este último, participaron las ciudades de Toluca (Universidad Autónoma del Estado de México, Universidad de las Américas) y Guadalajara (Instituto Tecnológico de Estudios Superiores de Occidente). Poco tiempo después, decidí replicar la investigación en San Luis Potosí bajo el título 'Descubriendo la Sexualidad y la Sexualidad en los Medios', ya que el proyecto podía explorar el impacto que puede tener en la salud el consumo de los medios por parte de los adolescentes; conocer de primera mano lo que en realidad piensan y las formas en cómo actúan; cómo los medios de comunicación y el entretenimiento mediático afecta el desarrollo de conceptos como 'salud', 'cnfermedad' y 'prevención de enfermedades'; así como el uso que los adolescentes hacen de los medios en cuanto a la búsqueda de información respecto a la prevención del VIH/SIDA, el consumo del tabaco, el uso del condón, etc. Occidente

* Centro de investigaciones y estudios superiores en antropología social - 
El proyecto también permitiría indagar sobre uno de los temas que se tocaban lateralmente y era lo relacionado a la sexualidad juvenil. Por lo demás, la investigación no sólo daría fe de los adolescentes como grupo etario, sino que el acercamiento a las juventudes inevitablemente provocaría reflejos del mundo adulto y la sociedad con quienes conviven.

\section{Limitaciones}

Un estudio siempre tiene limitaciones y el presente trabajo no está, excento de éstas. La primera gran restricción a la que se enfrentó fue la delimitación de la investigación al no aplicar el protocolo con las adolescentes por cuestiones de tiempo. A pesar de que en algunos grupos focales salieron a relucir cuestiones de género, así como ciertas opiniones de cómo los varones creen que piensan y actúan las mujeres en cuanto a la correspondencia entre los medios, la salud y la sexualidad, la voz de ellas se hace precisa para entender de manera más completa y compleja las relaciones, experiencias y percepciones a las que 1@s adolescentes se enfrentan. Además, los datos encontrados bien pudieran complementarse con información estadística para darles mayor extensión, sin embargo, los plazos, dineros y circunstancias no permitieron la realización de una encuesta.

\section{Marco Referencial}

Los estudios de las juventudes han aparecido en la escena mundial hace poco tiempo. El crecimiento de las grandes ciudades occidentales hizo visible los escenarios de las sociedades complejas y la configuración de nuevas maneras sociales de ser y actuar. Es en la ciudad donde los jóvenes mayoritariamente se concentran, el ámbito que se considera "no sólo como un fenómeno físico, un modo de ocupar el espacio, sino también como lugares donde ocurren fenómenos expresivos que entran en tensión con la racionalización, o con las pretensiones de racionalizar la vida social" (García Canclini, 2003). Un "espacio de investigación prioritario y privilegiado, en la medida en que no es solamente el escenario de las prácticas sociales, sino fundamentalmente el espacio de organización de la diversidad, de los choques, negociaciones, alianzas y enfrentamientos entre diversos grupos sociales por las definiciones legítimas de los sentidos sociales de la vida" (Reguillo, 1995: 122). 
La ciudad, por tanto, comprende actores quese encuentran dentro de marcos sociales que determinan su posición, y que orientan sus representaciones y acciones (Jiménez, 2002: 39). Esto refiere a la construcción social de la identidad, que es un proceso tanto individual como social: "mientras que la identidad social es una síntesis de la dialéctica de las definiciones internas que hace el actor acerca de sí mismo, así como de las definiciones externas que le dicen al actor lo que los demás actores le dicen que es, la identidad individual se deriva de los procesos tempranos de socialización. Se trata de las identidades primarias, que son por lo mismo más fuertes y las más resistentes al cambio" (Chiuh, 2002: 6).

La identidad no sólo es un proceso interior, sino básicamente un proceso social y un "producto de las relaciones sociales" en el que la alteridad juega un papel decisivo, donde necesariamente existe una relación de inclusión - exclusión que se ubica en espacios no necesariamente físicos, sino muchas veces simbólicos, y refieren a fronteras que "permiten definir quiénes pertenecen al lugar (y obtienen una identidad positiva) y quiénes deben ser excluidos (y obtienen una identidad negativa)" (p. 6). Por esto, los jóvenes como sujetos sociales componen

un universo social cambiante y discontinuo, cuyas características son resultado de una negociación-tensión entre la categoría sociocultural asignada por la sociedad particular y la actualización subjetiva que sujetos concretos llevaban a cabo a partir de la interiorización diferenciada de los esquemas de la cultura vigente (Reguillo, 2000).

La identidad juvenil, pues, no se construye a partir de un espacio físico o una categoría cerrada cuyos límites de acción están regulados y normados, sino a partir de la diversidad de prácticas sociales y la forma en que se realizan dentro de un determinado espacio social.

La posibilidad de sostener que puede hablarse de un sujeto juvenil, presupone la elaboración de múltiples articulaciones, que ancladas efectivamente en unos rangos de edad, sean capaces de dar cuenta de los arraigos empíricos en que esa edad deja de ser dato natural y se convierte en un revelador de modos particulares de experimentar y participar del mundo.... Para intentar comprender los sentidos que animan a los colectivos 
juveniles y a los jóvenes en general, hay que desplazar la mirada de lo normativo, institucionalizado y del 'deber ser', hacia el terreno de lo incorporado y lo actuado; buscando que el eje de 'lectura' sea el propio joven que, a partir de las múltiples mediaciones que lo configuran como actor social, 'haga hablar' a la institucionalidad ( $56-57,69)$.

Una institucionalidad relacionada, "crecientemente interconectada" por los medios de comunicación que se convierten en espacio fundamental, y que contribuyen a la formación de la sociedad en donde, de manera especial, la televisión se ha convertido en "la gran proveedora de imágenes y discursos para leer el mundo". Los medios se han transformado de tal modo, que incluso han pugnado con las "instituciones tradicionales la hegemonía en la construcción de los sentidos sociales de la vida" (Reguillo, 2003: 81), a la vez que la pantalla chica se ha convertido en "la autoridad cognitiva más importante de los grandes públicos", en la vocera legitimada de la 'realidad' por la cual non vidi, ergo non est (Sartori, 1997: 114).

Al respecto, Orozco (1995: 260) declara que aún cuando el proceso de transmisión y recepción de los contenidos no es tan sencillo como se pensó originalmente, ya que la visibilidad del proceso se ha trastocado, y la comunicación se

Descentra debido a: a) la diferenciación intrínseca de los medios, b) la amplificación del potencial técnico de los diferentes instrumentos involucrados en la circulación de la información, y c) la activación de diferentes mediaciones en el proceso, reales pero intangibles.... también sabemos que, a través de las propiedades físicas que ha conquistado y de los hábitos culturales que ha formado, la televisión cuenta con un alto margen de eficacia persuasiva comprobada para crear y cambiar las formas de pensar y actuar en México.

En parte, por esto la comunicación ha dejado de ser solamente una cuestión de medios para referirse más bien a las mediaciones, como lo apunta Jesús Martín Barbero. El espectador se entiende entonces como "un sujeto histórico, situado, capaz de intervenir en su realidad" (Reguillo, 1995: 111). 


\section{Metodología}

La investigación realizada en San Luis Potosí corresponde a una metodología ya establecida de antemano por un grupo de académicos que participan en el Proyecto de COMSALUD. Sin embargo, cada país modificó según sus circunstancias los tiempos de las técnicas y las formas prácticas de aplicarlas. La pregunta eje del proyecto era: ¿Cuál es y qué características tiene el rol de los medios de comunicación en la cotidianeidad de los adolescentes en América Latina, particularmente en el ámbito de la salud?

La tecnología quedó definida en dos etapas ccimplementarias: una de corte cualitativo a través del uso de la técnica de grupos focales, y la segunda de corte cuantitativo con el uso de una encuesta -que como ya se mencionó, no se aplicó en San Luis Potosí. "Dado que se estableció que el trabajo era un estudio exploratorio, se privilegió un acercamiento mayor sacrificando la profundidad del discurso, apostando a tener el mayor y más diverso discurso sobre el tema". Los guiones de los grupos focales para el proyecto "La voz de los adolescentes' se elaboraron por parte de "la coordinación central del proyecto; las dificultades radicaron en la extensión del mismo incompatible con una dinámica de grupo focal de dos horas y un promedio de ocho integrantes por grupo-, por ello se hicieron guiones sintéticos y se priorizaron ejes de diálogo más que preguntas" (M. M. Collignon, comunicación personal, 26 de noviembre de 2002).

La población adolescente de 12 a 19 años se constituyó como el universo del estudio, teniendo en cuenta que la OMS reconoce como adolescentes a las personas comprendidas entre los 10 y 19 años, y como jóvenes a quienes se encuentran entre los 15 y 24 años.

"Todos los estratos socioeconómicos estaban incluidos y delimitados en las categorías de clase baja, media y alta; así como las poblaciones urbanas, semiurbanas, rurales e incluso poblaciones indígenas"; clasificándose a la población hasta en escolarizados y no escolarizados. Por "cuestiones de recursos económicos se tuvo que tomar la decisión de trabajar en todos los países sólo con dos estratos sociales (bajo y medio) y dos poblaciones (urbano y semiurbano)". Esto produjo que se delimitara aún más el proyecto, y se eliminó el estudio de los sectores no escolarizados.

Los grupos focales podían llevarse a cabo "en cualquier espacio que permitiera reunir a los jóvenes, desarrollar la actividad y trabajar cómodamente" (2002); por lo tanto, las escuelas eran la opción más 
viable para realizarlos al tener a un segmento de los sujetos de estudio en un solo espacio.

La condición para seleccionar a las instituciones se refirió a la clase económica, definida por el prestigio de la escuela, su ubicación y elementos identificatorios como el tipo de zona, servicios, calle, banquetas, viabilidad, instalaciones de luz y teléfono, así como la vegetación existente.

Sin embargo, había que tener en cuenta el resto de las variables edades, pertenencia territorial-, y se decidió que las escuelas no podían estar geográficamente cercanas unas de otras para evitar al máximo la posible similitud del discurso, o el conocimiento de los participantes; además de tener el suficiente número de alumnos para evitar que los adolescentes se conocieran y el discurso se homogeneizara. Las escuelas seleccionadas se muestran en el siguiente cuadro:

\section{Cuadro 1}

\begin{tabular}{|l|l|l|l|l|}
\hline \multicolumn{3}{|c|}{ Clase Media } & \multicolumn{2}{c|}{ Clase Baja } \\
\hline 12-15 años & Urbano & Semiurbano & Urbano & Semiurbano \\
& $\begin{array}{l}\text { Colegio de } \\
\text { Bachilleres } \\
\text { No. 1, } \\
\text { Halcones. }\end{array}$ & $\begin{array}{l}\text { Instituto } \\
\text { Salesiano } \\
\text { Carlos } \\
\text { Gómez }\end{array}$ & $\begin{array}{l}\text { Escuela } \\
\text { Secundaria } \\
\text { Jaime Torres } \\
\text { Bodet. }\end{array}$ & $\begin{array}{l}\text { Escuela } \\
\text { Secundaria } \\
\text { Técnica 79 }\end{array}$ \\
\hline 16-19 años & $\begin{array}{l}\text { Centro } \\
\text { Científico y de } \\
\text { Estudios } \\
\text { Superiores No. } \\
1, \text { Turno } \\
\text { vespertino. }\end{array}$ & $\begin{array}{l}\text { Instituto } \\
\text { Salesiano } \\
\text { Carlos }\end{array}$ & $\begin{array}{l}\text { Centro } \\
\text { Científico y } \\
\text { de Estudios } \\
\text { Superiores } \\
\text { No. 2, Turno } \\
\text { vespertino. }\end{array}$ & $\begin{array}{l}\text { Científico y } \\
\text { de Estudios } \\
\text { Superiores } \\
\text { No. 3. }\end{array}$ \\
& & & Centro \\
\hline
\end{tabular}

El análisis del discurso que se utilizó fue la técnica del análisis argumentativo, pues "permite construir esquemas de representaciones lógicas de lo que se piensa y se dice en situaciones concretas de enunciacíón" (Chávez, 2001: 174). Además de que estaba trabajando con una textualidad discursiva, la de los adolescentes. Opté por utilizar el procedimiento que ha practicado al respecto el Dr. Jesús Galindo y 
que consiste en sintetizar el discurso en partes mínimas pero cargadas de significado (1992: 183); sentido que refleja el discurso propio de los adolescentes en relación con la mirada del analista, hasta lograr una imagen de las representaciones mentales de los participantes.

Las categorías de análisis fueron elaboradas por los investigadores latinoamericanos tomando en cuenta dos niveles, el primero correspondía a cada variable del proyecto, y el segundo a una taxonomía que pudiera expresar dicha variable. Sin embargo, al momento de analizar los grupos de San Luis Potosí, decidí modificar las categorías en función de la ventaja que me ofrecía para el análisis una redistribución, o la aplicación de nuevas categorías que los mismos adolescentes en su discurso iban de un modo u otro generando. De tal forma, la categoría de "Acceso" de los medios la subordiné a la de "Medios", puesto que si bien sí existe una diferencia en el acceso a los medios según la clase social de la que se trate, dicho acceso se relaciona de manera directa con el uso de los medios, el interés por cada uno de estos, y las posibles lecturas que los adolescentes tienen de ellos.

Además, las categorías de "Información", "Salud" y sus derivaciones, no solamente las limité a la información que los adolescentes reciben de los medios, sino que abrí la categoría a cualquier fuente de información y a cualquier mensaje sobre salud que recibieran, en el entendido de que la recepción no puede enfocarse solamente al medio y al receptor, sino a todo un juego de massmediaciones en los que intervienen otros actores, instituciones sociales y circunstancias.

Lo mismo hice con las categorías de "Percepción" y "Usos de la Información" puesto que los "ricios de valor de los adolescentes no se dirigían solamente a la información sobre salud y, si bien es cierto que la delimitación del objeto de estudio se enfoca en una de sus líneas a la salud, al abordar también a los adolescentes como objetos/ sujetos de estudio, no se pueden dejar de lado las apreciaciones sobre sus entornos -padres, familia, amigos, escuela, medios, globalización, género- que finalmente les permiten tener una lectura propia de su realidad y también de la salud: son sujetos que están construyendo su discurso de una manera histórico-social, en un hábitat mediatizado y globalizado.

En cuanto a la categoría de "Contenidos", agregué las subcategorías de "Tabaco" y "Condón". La primera fue una constante en todos los grupos tanto de Guadalajara como de San Luis Potosí, lo 
que habla de la relevancia de este tema entre los adolescentes y la especificidad que en el análisis debía de tenerse en cuenta. Así como el condón, que si bien puede estar relacionado con las subcategorías de sexualidad o del VIH/sida, los contenidos discursivos se enfocaban de una manera particular al preservativo bajo diversas ópticas, por lo que analíticamente y según mi apreciación, merecía más consideración este tópico. La categoría de "Otros" no encontró eco en los discursos al centrarse más en el tabaco y el condón, y se eliminó.

Finalmente se agregaron dos categorías más, la de "Padres/Adultos" y la de "Género". La primera categoría que trabaja como un binomio, resultó de la frecuente mención de los padres y los adultos en general por parte de los adolescentes, como imagen simbólica de quien está sobre ellos. Y si bien los adolescentes hablan de un mundo adulto, además identifican en este universo a los padres, a quienes se les atribuyen características específicas con relación, sobre todo, a la manera en que son educados en las diversas áreas de sus vidas, y al uso diferenciado de los medios. La categoría de "Género" no aparece en todos los grupos en primera instancia como la de "Padres/Adultos", pero sí es de llamar especial atención el que en algunos de ellos se discutieran guiones sexuales masculinos y femeninos. En algunos casos sólo para reafirmar estereotipos de cómo son las mujeres, y en otros, para manifestar su rechazo y discusión abierta sobre los guiones machistas acerca de la masculinidad.

\section{Resultados Medios}

La televisión se perfila sin duda como el medio más importante para los adolescentes en cuanto a relevancia, uso y gusto, sin importar la clase social. Goza, además, de la credibilidad en la mayoría de los adolescentes de clase baja, mientras que en la clase media ésta empieza a ser desplazada poco a poco por el Internet, que comienza a generar una creciente afición como medio preferido por su propia configuración: un conjunto de páginas electrónicas con ingreso permanente, en el que hay libertad de acceso a los contenidos.

En cuanto al uso de los medios, hay una propensión en los adolescentes de la clase media a utilizarla solos, mientras que en la clase baja, el uso de la televisión, por ejemplo, se realiza en compañía de los hermanos de manera más frecuente, así como de los amigos y familiares. En la clase baja el consumo del medio se hace en familia, 
provocando que existan disputas sobre los contenidos que se quieren ver por una parte, pero en ocasiones también reúne a sus miembros entre semana para ver un programa en específico. Mientras que los chavos de clase media utilizan los medios en sus propias casas y de manera individual la mayor parte de las veces, los jóvenes de clase baja frecuentan a sus amigos en sus casas y utilizan juntos los medios como la televisión o el radio.

Para los de clase baja, la imagen es un referente inequívoco de la verdad. Lo que la televisión muestra es una prueba empírica, real y concreta de lo que sucedió, cualidad que ningún otro medio comparte, exceptuando el Internet. Además de que la televisión tiene la facultad de estar presente en el momento justo en que la noticia se está desarrollando. Para los de clase media, la televisión tiene la capacidad de mentir, al ser manipulables sus contenidos y existir la corrupción de los adultos, quienes con dinero pueden modificar los mensajes que se transmiten.

Dos terceras partes de los adolescentes de clase media tienen acceso al sistema de televisión por cable, y en similar proporción tienen acceso a Internet en sus propias casas. El resto tiene sistema abicrto de televisión, y para consultar el ciberespacio rentan computadoras en cibercafés, aún cuando el uso de la Web se da en todos los participantes. La clase baja, mientras tanto, solamente tiene acceso al sistema de televisión abierto, y el Internet si bien es usado por un número considerable de participantes, todavía hay algunos que no lo utilizan, sobre todo porque para acceder a éste hay que invertir dinero que no consiguen tan fácilmente -al menos dos quintas partes de los adolescentes de clase baja laboran para contribuir a la economía familiar directa o indirectamente-, o porque el acceso a la tecnología no ha sido tan fácil como con la clase media, en donde al menos en cada hogar hay una computadora, aunque no tenga Internet. La abrumadora cantidad de páginas en inglés que imposibilitan su lectura, y el hecho de que algunos adolescentes declaran no saber utilizar el navegador, son otras limitantes.

Para los de clase baja, el uso del radio ocupa el segundo lugar en el listado de los medios en cuanto a uso, y entre el segundo y tercer lugar en importancia, además que declaran es barato utilizarlo, puede llevarse a donde uno quiera y acompaña en las actividades diarias como realizar tareas, trabajar, etc. También les permite estar en conexión con lo que sucede en la ciudad, y es un vehículo informativo que los ubica socialmente en lo local. 
Respecto al periódico, algunos adolescentes de ambas clases lo consultan porque sus padres lo adquieren; pero son muy pocos quienes llegan a comprar un diario. Las secciones que se consultan son similares: deportes, espectáculos, clasificados y las tiras cómicas. Para los adolescentes de clase media, el rotativo es uno de los medios más creíbles por la profundidad de la información que contienen, mientras que para muchos adolescentes de clase baja, es un medio difícil de entender.

En general perciben que los medios funcionan bajo un sistema emisor-receptor, lo que aseguran no los motiva a interesarse por contenidos que salgan del ámbito del entretenimiento, sobre todo cuando se trata de mensajes de salud que implican cambios en las conductas o toma de decisiones. Los jovenes esperan que los medios cambien a un sistema en el que se les reconozca su papel activo como adolescentes y haya contenidos mediáticos que los involucren de una manera activa y no pasiva -como simples espectadores.

Afirman que el consumo de la televisión, en concreto, ejerce una gran influencia en sus vidas y les ayuda a formar su criterio y, al mismo tiempo, refieren que los medios están envueltos en el mundo de la corrupción y están dispuestos a venderse al mejor postor; de este modo, la 'verdad' que pregonan puede ser un axioma pagado al que ellos están expuestos a creerle. Ésta es una de las razones por las que los adolescentes han externado su deseo de que los padres y maestros, pero sobre todo los primeros, no solamente les informen lo relativo a la salud y la sexualidad, por ejemplo, sino que los eduquen y les ayuden a formar un criterio para decidir sobre sus vidas y la manera de entender la información que ellos reciben de las múltiples fuentes con las que están en contacto.

Los jóvenes muestran dos posturas ante la televisión: una minoría la percibe como un enemigo que atenta contra los valores familiares, que promueve la violencia y que cada vez contiene más "basura"; la otra, más critica, en donde se le reconoce su papel socializador, su importancia como elemento mediático que llega a una inmensa audiencia, su gran poder, pero también la facilidad con la que puede manipular sus contenidos y hacerlos pasar como verdaderos ante una buena paga. 


\section{Salud}

Los conceptos de salud que los adolescentes manejan, en gencral se refieren a percepciones físicas del momento y a un bienestar que se responde con no experimentar incomodidad en el cuerpo en un momento determinado, $o$ al desarrollo de éste bajo cánones sociales que los mismos medios han ayudado a imponer: delgadez, músculos marcados y con tono, dictas equilibradas, ejercicios reductivos.

Si bien algunos buscan ejercitarse para incrementar su musculatura y desarrollar una imagen que los medios publicitan -aún cuando sus cuerpos son perfectamente equilibrados-, también es verdad que la propia figura que se busca modificar no es un fin per se, sino que está en función de los otros o las otras, pues modificar su cuerpo bajo ciertos cánones tiene objetivos específicos como ganarse la admiración de las chicas, o llamar la atención de los varones mismos, en cuanto a provocar consideración de su parte.

La salud la entienden como lo opuesto a la enfermedad y a lo que impide realizar las actividades comunes y cotidianas, por lo que se concibe como un elemento que se posee de facto, que queda en planos posteriores en la mente de los jóvenes. Aseguran que se preocupan por su salud a partir de una responsabilidad que se asume como propia, pero que no se ejerce. Para unos pocos, la salud es un tema que cobra relevancia en tanto se vincula con el bienestar inmediato del propio cuerpo del adolescente.

Solamente cuando el equilibrio del cuerpo se rompe y éste se manifiesta de una manera no usual o con síntomas patológicos, el tema de la preocupación y ocupación de la salud viene a la mente y acción de los chavos, tomando el primer sitio.

Ellos reciben información sobre sexualidad, salud y prevención sexual en la escuela, y algunas veces en su hogar y a través de los medios. Saben que hay enfermedades de transmisión sexual y riesgos económicos y sociales en el uso de su sexualidad -embarazos no descados, transformación del estatus de estudiante a mano de obra poco calificada, insuficiente apoyo emocional y/o económico de los padres o familiares.

En cuanto a los medios, si bien transmiten información relativa a la salud, solamente se limitan a reproducir spots pagados o del gobierno, pero no refieren contenidos de salud más allá de las producciones del Canal 11 del Politécnico: Diálogos en Confianza y Sexo Diario. Cuando algún canal llega a transmitir temas rclativos a 
la sanidad, se limitan a un solo programa, restringido además por el tiempo que debe compartir con los patrocinadores, $y$ en donde el grado informativo que proporcionan es mínimo.

Los mensajes de salud que los adolescentes identifican en los medios son, a saber: campañas de vacunación infantil, abrigarse en temporada de frío, y consumo de frutas y verduras por parte de la SSA; anuncios de planificación familiar de CONAPO; la campaña anti-drogas de TV Azteca "Vive sin Drogas"; anuncios que venden productos para dejar de fumar, para solucionar la impotencia sexual y la eyaculación precoz; así como spots que promueven el uso del condón, conocer a la pareja sexual y evitar múltiples parejas como mecanismo de prevención del VIH/sida, por parte de CONASIDA y de la empresa de condones Sico.

Para los chavos, los mensajes de prevención a la salud que transmiten los medios en ocasiones no son suficientes para que tomen sus precauciones, pues el uso de su sexualidad -o la de sus amigossin métodos preventivos, por ejemplo, sigue siendo fenómeno recurrente. Además, los spots utilizan un lenguaje que da por hecho que ellos entienden las cosas que emiten, aunque en algunos de los casos no es así; o no dicen las cosas por su nombre, tal y como son, sino promocionando conceptos o contenidos ambiguos, o que refuerzan ideas sobre la salud, el cuerpo y la sexualidad como tabúes. Los adolescentes comentan, además, que los mensajes de prevención a la salud tienen un efecto contrario a lo que se busca. Es decir, en vez de prevenir que se droguen, por ejemplo, les despierta el interés y la curiosidad por hacerlo.

Todos los adolescentes de los grupos focales hicieron notar la gran contradicción que existe en los spots de cigarros y alcohol, ya que al mismo tiempo que promueven su consumo, desalientan el mismo a través de leyendas como "nada con exceso, todo con medida", "el tabaco puede causar cáncer", "fumar puede causar enfisema pulmonar". Y si bien es cierto que algunos saben que esta medida es sólo una obligación reglamentaria por ley para la transmisión de los spots en los medios, la mayoría lo entiende como la gran paradoja que se refleja también en lo cotidiano, es decir, los adultos no quieren que los chicos fumen o beban, pero ellos son quienes les han puesto el ejemplo.

Por esta razón, los jóvenes aducen experimentar una dicotomía en el sistema en el que viven: son considerados inmaduros e irresponsables, no niños ni tampoco adultos, sino aprendices de los 
mayores a quienes deben de seguir con el ejemplo. Además, les informan sobre los riesgos de la sexualidad en varios grados de profundidad y extensión -no siempre a un nivel deseable-, y se espera de ellos que con dicha información actúen de manera tal que cuiden su salud, pero como en los anuncios de cigarros y alcohol, las letras preventivas son pequeñas en comparación con el mensaje completo del spot.

A partir de la prohibición de venta de cigarros a los menores de edad por parte de la Secretaría de Salud en el año 2002, los menores que fumaban sí constataron que en las tiendas les negaban los cigarros si no mostraban una identificación que los acreditara como mayores de 18 años. Pero a pesar de ello, los comerciantes si bien rechazaban vender uno o dos cigarros, o cuatro o cinco -es decir, al menudeo-, no se negaban a vender cajetillas enteras, so pena de perder la ganancia. Para algunos chavos, la utilización tanto del cigarro como el alcohol cumple también una función simbólica, es una especie de rito iniciático de la niñez a la adultez: "echarse" un cigarro equivale a "hacerse hombrecito", o una forma simbólica de aparecer como 'más' hombre frente a otros, en medio de un complejo entramado de roles genéricos y de entornos moldeados por clases sociales y edades.

Aparte de lo ya mencionado, en un grupo surgió el interesante caso de un adolescente que tienen un estilo de vida saludable y que busca conscientemente que así sea: cuida su alimentación, va al gimnasio, busca información relativa a la salud y cómo mejorarla, al ser sexualmente activo busca protegerse; además de consultar sus dudas sobre salud y sexualidad con personas competentes y en el Internet. Sin embargo, mostró una excesiva preocupación por la sanidad que se refleja en su interés de realizarse a los 17 años un examen de próstata y comunicó su miedo a utilizar el método de inspección para esta clase de exploraciones, que es el anal. El chico en cuestión tiene relativamente poco tiempo viviendo en San Luis Potosí, y es procedente del Distrito Federal.

Los jóvenes solicitan que los medios promuevan información sobre las ETS en cuanto a qué son, cómo se transmiten, qué efectos tienen y cómo pueden tratarse si llegan a enfermarse, aún cuando al mismo tiempo han declarado qué estas son las temáticas principales que les imparten en las instituciones educativas a las que pertenecen. En mayor o menor grado, los chavos afirman estar conscientes que de ellos mismos depende tomar sus propias decisiones y afrontar sus consecuencias, aunque aceptan que los medios pueden ayudarlos a 
decidir criterios importantes en sus vidas. Por ello, los grupos coincidieron en que la forma de mejorar los spots es haciéndolos impactantes, con imágenes que provoquen recordarlas en cualquier momento, y que los ayuden a cambiar su circunstancia o decisión de riesgo sexual por una medida de protección. También deben presentar información detallada para que analicen los casos en los que se encuentren, y decidan qué hacer en su propia vida, mostrando modelos juveniles reales, más atrayentes $-\mathrm{y}$ no con caricaturas-, en donde se manifiesten conductas y comportamientos que se desenvuelvan en ambientes de riesgo, mostrando las consecuencias de aceptar el peligro a la salud en sus conductas al mismo tiempo.

En cuanto a los programas mediáticos de salud y/o prevención para que funcionen, aseguran que deben ser dirigidos por los jóvenes y no por los adultos; tener debates con gente especializada que resuelva sus dudas; contener información especializada, sobre todo de ETS para tratarlas y curarlas; así como contar con historias reales, y presentar un análisis al final en donde se muestre lo que llevó al joven a actuar de determinada manera. A fin de cuentas, involucrarlos de manera activa para que tengan un comportamiento saludable, y los comprometa incluso físicamente; además, estimular un espíritu de competitividad entre los chavos respecto a la salud.

\section{Adolescentes y Sexualidad}

Los adolescentes hablan de un mundo adulto que los conceptúa como personas que están en formación, que no deben comportarse como niños y que, al mismo tiempo, no tienen todavía la capacidad de actuar al modo de aquéllos. Algunos incluso declararon que cuando sus padres los conceptúan como inmaduros y esperan que actúen de una forma 'madura', actúan de la manera contraria como forma de contradecirlos. Sin embargo, los chavos platican que si bien apenas están formando sus propios criterios éticos, por ejemplo, no por ello dejan de ver la realidad en la que viven: ellos se preocupan y angustian por las situaciones sociales que se experimentan no sólo en San Luis Potosí, sino incluso en el mundo, como la guerra de Irak contra Estados Unidos, y la volatilidad e incertidumbre económica de los diversos países y sus consecuencias globalizantes para otros. Además, constatan que la juventud se está convirtiendo en una especie de chivo expiatorio, en el cual el mundo adulto carga sus propios 'pecados', cuando en 
realidad son éstos quienes han formado el mundo que los adolescentes apenas están conociendo y experimentado.

Los jóvenes declaran aparecer ante muchos adultos sólo como un grupo social en el que pueden descargar hechos que la misma sociedad ha generado y que la laceran constantemente -violencia, robos, inseguridad, miedo.

El grupo de adolescentes de clase baja entre 12 y 15 años manifestó ideas interesantes acerca de la concepción de la juventud en la sociedad, y las relaciones que los adultos riantienen para con ellos. Las imágenes centrales corren sobre el supuesto adulto de que en todas las escuelas de los adolescentes abundan las drogas, así como que son los jóvenes los responsables de todo lo malo que pasa en la sociedad, en cuanto que son ellos quienes incrementan la violencia en la ciudad, quienes grafitean y afean las calles invadiendo la propiedad privada; quienes en la noche dominan las travesías urbanas a base de provocaciones, golpizas y robos.

En cuanto a la sexualidad, algunos adolescentes de clase media se experimentan como parte de una nueva generación que tiene la posibilidad de hablar y discutir al respecto de una manera más abierta, a diferencia de las generaciones de sus padres cuando éstos fueron jóvenes.

En las clases bajas, si bien se registran cambios en cuanto a la apertura de la información sobre sexualidad, persiste aún el miedo a abordar estas temáticas, así como la idea de la sexualidad como un bien propio del mundo adulto, y la concepción de los adolescentes como niños. Esta cerrazón se refleja incluso en las propias relaciones que establecen algunos adolescentes con sus pares, pues el tema de la sexualidad en ocasiones ni se menciona, aunque a veces se tenga la curiosidad o la intención de hacerlo. Al respecto, un adolescente en cuya familia nunca había existido una televisión sino hasta hace algunos meses, al hablar sobre las personas que tienen VIH, comentó que él no conocía a alguien con esta enfermedad, pero sí a "perros con sida", y que a él le daría temor sentarse junto a una persona que portara el virus porque sentiría que le brincaría y se le pasaría.

Aún así, en el mismo grupo se presentó un caso de cambio de posición en torno a la sexualidad: un adolescente comentó que habiéndose iniciado sexualmente semanas antes de la realización del grupo focal, cambió su idea respecto de que era algo sagrado y debía realizarse hasta después del matrimonio, por una concepción de posibilidad de gozo y placer compartido con una pareja. 
Los chavos refieren que para algunos de sus padres y para algunos adultos, la sexualidad adolescente es vista como una perversión, ya que pensar en ella en esta ctapa, o aún más suponer su ejercicio, no corresponde con una evolución normal de la persona. Algunos otros, sólu permitirían a los adolescentes tener relaciones sexuales cuando estos tuvieran la capacidad de sostenerse cconómicamente por sus propios medios; mientras que ciertos padres consideran a sus hijos como personas con una sexualidad enardecida $\mathrm{e}$ incontrolable a la que es preciso domar.

Para muchos jóvenes de los grupos focales, la sexualidad y su ejercicio no es una perversión, sino una parte integral de la persona que debe ser explorada y disfrutada en tiempos, formas y situaciones concretas. Además, dan fe que los padres no saben cómo lidiar con la scxualidad de los hijos, sea "indomable" o no. Se limitan a decirles que se cuiden, sobre todo cuando tienen novias, como si tal hecho llevara inmediatamente a tener una relación sexual, lo que no siempre es así.

Los adolescentes de clase media dan fe que ellos de una u otra manera han recibido información sobre el VIH/sida y la sexualidad; en algunos casos ha sido suficiente, y en otros, es necesaria más información, tanto en la escuela, como en la familia y los medios. En general, todos los dan cuenta que la información que los padres les dan sobre sexualidad, cuando lo hacen, se enfoca en ocasiones más a las consecuencias de una relación sexual que a la formación de su sexualidad.

Los adolescentes pidieron en los grupos focales en general que se les otorgue una formación en su criterio, pues son ellos -como lo afirman- quienes decidirán en última instancia sobre sus actos, y que la prevención sexual, por ejemplo, no depende de los spots en los medios, sino de ellos, pues de una u otra forma saben "a lo que le tiran". Esperan entonces que junto con la información, se les brinde una educación puntual y particular, lo que consideran excede el actual papel informativo en que los medios, la escuela y/o la familia han tomado parte. Experimentan como una necesidad el saber cómo utilizar la información que se les otorga, en qué momentos, en qué contextos, con qué valores élicos y morales.

Revelan además la urgente necesidad que tienen de que los padres, la escucla y los medios profundicen sus contenidos formativos sobre la sexualiclad, puesto que si bien intuyen que de ellos depende su propia salud y su futuro, al no tener una educación de respaldo, no 
saben cómo responder ante las consecuencias de su sexualidad "por la ignorancia".

Algunos adolescentes preferirían que la formación de la sexualidad proviniera principalmente de su familia más que de la escuela y/o los medios, sobre todo porque en sus miembros pueden sentir mayor confianza; mientras que otros aducen que si los medios de comunicación dieran la información que necesitan, y les inspiraran confianza para hablar a centros de asesoría en los que encontraran tal vez la formación que tanto buscan, no recurrirían a sus familiares.

Para ellos, los tabúes que siguen rodeando a la sexualidad, así como la presión social de no aparecer como menos ante el otro, impiden que despejen sus dudas sobre sexualidad cuando se les presenta la oportunidad -en la escuela, por ejemplo. $Y$ aunque saben que si no aprovechan esa oportunidad, será más difícil volver a obtener dicha información después, prefieren quedar "en la ignorancia", lo que los conduce a una especie de cadena en donde tienen dudas sobre la sexualidad, la oportunidad de despejarlas, y no lo hacen.

Luego, cuando se les presenta la ocasión de experimentar la sexualidad, y al no tener información, se encuentran en una situación de riesgo sin saberlo o sin tener la información necesaria para que deje de ser un peligro, y pueden terminar contrayendo una enfermedad o embarazando a alguien.

Los adolescentes que tienen una vida sexual activa, generalmente olvidan los mensajes de prevención sexual cuando están en el preludio de una relación, o si los recuerdan, la excitación del momento y/o el deseo de no perder la oportunidad de sexar los llevan a no utilizar algún método de prevención. Sin embargo, si la decisión de tener la relación viene por parte de la mujer, los hombres se detienen a pensar más en las posibilidades que tienen de contagiarse, por lo que tratan de recabar información sobre la situación y sobre la chica misma, como forma de disminuir la incertidumbre y el riesgo.

En esta situación, a la información que reciban, sea de los amigos, de los conocidos del lugar en donde se encuentren, o de la misma chica en cuestión, se le otorga la veracidad de manera cuasi inmediata. Es decir, si un amigo le dice que con esa chica no hay que usar condón, no lo usarán. O si la chica les dice que es virgen ellos no usarán condón. En esto también interviene la belleza de la chica, pues si es alguien que les gusta y han estado queriendo tener una oportunidad de sexar con ella, y la coyuntura se da, no van a perder la 
oportunidad de tener la relación porque no tuvieron un condón a la mano.

Por otro lado, en algunos adolescentes la responsabilidad del cuidado y protección sexual se confiere a la mujer, y el hombre se deslinda de ésta, lo que algún adolescente consideró como el reforzamiento de la posición machista en las relaciones genéricas. En la transición de la búsqueda de la relación sexual, o la aparición de una oportunidad para el acto sexual, median muchos elementos que llevan a los adolescentes a tomar una decisión, y que pueden conjugarse o ser tan sólo unos cuantos.

Ante la situación hipotética de un embarazo, hay una diferencia en cuanto al tipo de respuesta que se daría según la clase social. Mientras que en la clase media algunos sí se casarían con la chica, o responderían de maneras en que no se obligaran a vivir con ella, o valorarían mucho más las circunstancias de la relación sexual y a la persona con quien se tuvo, en la clase baja la respuesta de casarse es casi inmediata, aunque en algunos casos pensarían en cuanto quieren a la muchacha o si la conocen.

En la posibilidad de que en una relación sexual el condón se rompiera, algunos adolescentes proseguirían sus relaciones sexuales. Además, la idea de comprar un condón no es atrayente para muchos adolescentes porque se confronta con las ideas que circulan entre ellos de que se siente más "chido" sin condón que con él; o no se tiene el dinero para adquirirlos; o no se tenía previsto su uso; o no se le encuentra sentido a usarlo.

Respecto al uso del condón, en el grupo de clase baja de 15 a 19 años, semiurbano, se desató una discusión respecto al hecho de que cuando los chavos declaran usar el preservativo en una relación sexual, no implica de facto que así sea, pues puede suceder que los adolescentes incluso traigan condones en su cartera, pero sólo para presumir, para demostrar que tienen la capacidad y oportunidad de tener relaciones sexuales, y que por ello se es hombre, aunque en los hechos nunca hayan tenido siquiera una sola experiencia.

\section{Conclusiones}

Los modos de utilización, compañía y apropiación de los medios por parte de los adolescentes varía según la clase social de que se trate: en la clase media se poseen más televisores, lo que permite que cada quien tenga su propio acceso al medio, pero también las relaciones 
al interior del núcleo familiar y con los amigos son más individuales; en la clase baja existe un televisor y es poco probable que haya más de dos, por lo que el uso y consumo del medio se da en familia o en la casa de los amigos.

Merece especial atención la utilización del Internet y lectura del periódico, en la que la clase media refleja mayores competencias de utilización, comprensión y lectura de formatos escritos, mientras que la clase baja ha hecho lo propio con el radio. Se trata, pues, de lecturas de los medios a partir de las competencias educativas que sus contextos les han posibilitado.

Se constata además, que la televisión se ha convertido ya no sólo en la niñera de los infantes y la compañía de los adolescentes, sino también en una formadora que va modelando en parte sus pautas de acción. Esto es tanto un riesgo como una enorme posibilidad al permitir incidir en conductas sanas y positivas, como negativas.

Con todo, los medios no son solamente entes ajenos o que actúen al margen de un contexto. Lo complejo del asunto es que los medios son empresas $y$, como tales, responden a intereses particulares tanto de la misma empresa como de las compañías que pagan su promoción en éstos. Y en dichos tratos no siempre existe una conciencia o una disposición a fortalecer y promover conductas de salud para la población en general, o en específico para los adolescentes.

En cuanto al concepto de salud que los adolescentes manejan, es un concepto inmediatista, es decir, si la estabilidad corporal se rompe a causa de un padecimiento, el adolescente enfoca su atención al tema de la salud, no por la importancia que ésta tiene per se como aseguradora de la sanidad in extenso, sino porque se quiere y se tiene que reestablecer el equilibrio corporal para realizar las actividades que de otro modo no se podrían ejecutar.

La salud se convierte entonces en un tonificante momentáneo, en un remedio que trae bienestar y no en un fin mismo. Por ello, al reducirse la salud a un medio y no a un fin, se confina a un estado momentáneo, de tránsito. Puede ser que este concepto sea el que impide, en parte, que las campañas de prevención de la salud, sobre todo en el aspecto sexual, tengan un efecto a largo plazo en los adolescentes. En un grupo de Guadalajara se mencionó que una vez que los adolescentes experimentan por ellos mismos que si no se abrigan bien en temporada de frío pueden llegar a enfermarse, como machaconamente les insistían sus papás y un spot de la SSA por televisión en su infancia -es decir, hasta que se enferman-, entienden 
el sentido de la prevención de la salud y entonces se apropian de la responsabilidad de abrigarse.

Además, en cuanto a información sobre prevención sexual que difunden las diversas instituciones, ésta se enfoca a evitar enfermedades que evolucionan en un cierto tiempo y que no afectan de manera inmediata -al menos visiblemente- al organismo. Los adolescentes al tener el concepto de la salud en un segundo plano, como medio y no como fin, no logran relacionar el riesgo con la prevención sexual, por ejemplo, porque en el escenario de la relación sexual no hay nada que evidentemente les ponga en peligro su equilibrio corporal, aún y cuando posean la información de las contingencias sexuales que la escuela, los medios y en ocasiones los padres les han brindado.

Este concepto de salud no refuerza la prevención, que funciona a largo plazo: una gripa provoca estornudos, lagrimeo en los ojos, nariz congestionada, dolor de cabeza -y es atendida de inmediato por los adolescentes-, mientras que una relación sexual implica placer visual, táctil; en ocasiones un deseo intenso de experimentación; ansiedad, nerviosismo, generación de expectativas socioculturales como presión de los pares para tener la relación; y tensión para actuar sexualmente 'bien' -guiones sexuales masculinos-, lo que no pone en funcionamiento el concepto de salud, y mucho menos el de prevención. Al ser la salud un concepto inmediatista, el riesgo a largo plazo no se detecta, o si se hace, no se le da la importancia necesaria. Aunado esto a la "cultura del riesgo" (Moore, 1996: 42) en la que algunos adolescentes viven y que los lleva a pensar que nada les va a suceder, como otras investigaciones norteamericanas han demostrado.

En una sociedad occidental de adultos que exigen a los adolescentes comportarse como aquéllos, y que al mismo tiempo no les reconocen su estatus de jóvenes, pero tampoco de niños, los adolescentes buscan mecanismos que los legitimen, según sus posibilidades y circunstancias, como un grupo diferenciado y que tenga peso al interior de la sociedad. El cigarro y el alcohol se convierten entonces en el pase de entrada a un nuevo mundo identitario que funciona como tal, al menos entre los pares. Ya que la sociedad no termina por definir el rol de sus miembros más jóvenes, éstos llevan la delantera al crear y recrear elementos y situaciones sociales dándoles nuevos significados que los identifiquen.

Al respecto, la prohibición para los menores de edad de fumar basada en la negativa de la venta de los cigarrillos, no encuentra eco 
en el sistema del mercado que prevalece sobre la salud pública, y aún más, muestra las contradicciones de un sistema que por un lado promueve la salud, pero por el otro no alienta las condiciones necesarias para instrumentar pautas que incidan de manera definitiva en la salubridad de la población. No se puede entonces esperar que los adolescentes adquieran conductas preventivas en cuanto a la salud se refiere-sexualidad, alcohol, tabaco, drogas-, si la información sobre la prevención y los tópicos diversos no se les otorgan con calidad, con una extensión y profundidad suficiente, y sin prejuicios ni tapujos. Además, los pocos mensajes de prevención a la salud que exisien deben competir con la infinidad de estímulos que los adolescentes reciben de su entorno familiar, social, urbano, escolar, barrial, de los amigos; de su clase social; del género al que pertenecen; de los lugares que frecuentan para divertirse; de su propia constitución fisiobiológica y sensorial, así como de la mercadotecnia tanto legal como ilegal a la que se exponen.

Los programas y campañas de salud deben enterarse de las necesidades concretas de los adolescentes y responder a ellas, ganar su confianza y hablar su mismo lenguaje. Aún más, involucrarlos en el proceso de desarrollo, aplicación y perfeccionamiento de los programas; así como decirles concretamente qué necesitan hacer en determinados escenarios, y quizá empezar a introducir técnicas de comunicación interpersonal que les ayuden a evitar riesgos en situaciones concretas de sus vidas. Conjuntamente, establecer una relación más directa entre la información de los spots, por ejemplo, y los servicios de asesoría de los organismos como CONASIDA o COESIDA.

En cuanto a la sexualidad, los spots reproducen la imagen de la sexualidad que los adultos viven y que los adolescentes no llegan a cntender: por una parte les proponen que se cuiden sexualmente, pero por otra no les dan la información suficiente, a detalle, ni los medios para que lo hagan. Se promociona entonces una sexualidad oculta que incita a develarse y experimentarse. $Y$ en este mar de confusiones, se encuentran en una dicotomía: entre la posibilidad de ejercer la propia sexualidad como joven, y saber que existen consecuencias graves que cambiarán su vida si no se cuidan.

No se trata en sí de una correlación simplista causa-efecto, como algunos grupos sociales quisieran verlo, sino más bien de toda una serie de mediaciones que los adolescentes tienen detrás de sí y les lleva a que la lectura del mensaje no surta el efecto deseado. Es 
necesario investigar más a fondo estas mediaciones y efectos de los mensajes.

Lo que los adolescentes manifiestan es que el proceso de asimilación de la información no es simple ni inmediato. Ver un spot de prevención a la salud sexual puede hacerlos pensar en el contenido un momento, pero no garantiza que se introyecte y se convierta en una actitud. Aún más, como mencionaban, puede tener el efecto contrario. Los mensajes necesitan estar acompañados de una información profunda e impactante que no necesariamente tiene que transmitirse en los medios, sino a través de programas escolares, por ejemplo, como ellos mismos enuncian.

La sexualidad en general por parte de los adultos, sigue siendo vista de manera conservadora y centrada en los valores judeocristianos: como un 'pecado' que sólo puede tolerarse cuando tienen como fin último la procreación. Dado que la procreación se espera dentro de una unión, que además de ritualizada sea aceptada socialmente, esto implica tener la mínima capacidad para sostenerse económicamente junto con la pareja y los posibles hijos. Las implicaciones de la moral conservadora se fundamentan, entonces, no sólo en los valores propios de la doctrina judeo-cristiana, sino inclusive en valores económicos.

Se trata de una medida precautoria que, transgrediéndola, puede desequilibrar el delicado sistema económico que las familias viven, sean de clase media o baja, así como el futuro económico del adolescente. La sexualidad adolescente entonces no sólo está mediada por normas sociales o culturales, sino que en el fondo también subyace una lógica de mercado en la que la domesticación de la sexualidad adolescente es factor clave para la supervivencia de un núcleo familiar. Pareciera que en el asunto de la sexualidad juvenil prevaleciera más el aspecto económico que el formativo y humano, es decir, los padres se preocupan más por las consecuencias económicas que un embarazo acarrea, y de las que de una u otra forma pueden ser responsables, que por el crecimiento, experiencia y formación de los hijos como personas. La sexualidad adolescente se encuentra entonces en la posibilidad de reducirse a un peligro económico y dejar de lado sus otras peculiaridades, como el placer, el descubrimiento, el gozo, etc. Existe además una ambivalencia en las respuestas que los adolescentes darían ante un embarazo no deseado, y en el caso de la ruptura del condón en un acto sexual: se adjudican su propia libertad y voluntad al decidir qué hacer en ambos casos, pero en realidad reproducen un 
esquema que el mundo adulto vive en la ciudad potosina: un embarazo no deseado tiene consecuencias externas, sociales, que modifican las prácticas y las conductas de los adolescentes, sobre todo para la adolescente. Es un suceso que modifica la corporalidad de ella y que evidencia socialmente su estado, confrontándose de manera directa con los valores y normas sociales que sobre la sexualidad adolescente existe por parte de los adultos. Los varones en general, como se mencionó, responderían haciéndose cargo de la chica y del próximo hijo, aún y cuando esto modifique su estatus de estudiante y adolescente, de modo tal que reconocerían que si bien transgredieron una norma social -tener una relación sexual-, aceptan 'enmendarse' $\mathrm{y}$ admiten por lo tanto la norma que dicta que ante un embarazo hay que casarse.

Es decir, hacia lo exterior, lo público, se acatan las normas y se aceptan los valores de la sociedad potosina que subyacen debajo de estas reglas -aún y cuando afecten a la vida individual, personal. Pero no sucede lo mismo en lo interior, lo privado, en donde los adolescentes deciden por ellos mismos y rechazan, en general, sea en la práctica o en el pensamiento, utilizar el condón en una relación sexual por diversos motivos, por ejemplo -lo que implica de facto romper otra norma social al tener una relación sexual en calidad de adolescente.

Lo que se descubre es que la sexualidad de los chavos refleja el mundo sociocultural que San Luis Potosí vive: un universo doble, paralelo, bifacético en cuanto a la moral, en donde al exterior se procura seguir la norma del conjunto social, y en lo privado se decide de manera individual, sin los influjos del medio.

El riesgo es evidente en tanto que es la misma dinámica sociocultural la que impide, también, un desarrollo de la prevención sexual. La moralina que se experimenta y se transmite a las nuevas generaciones se convierte en un gran peligro para la salud sexual de $1 @$ @ adolescentes, que puede en un santiamén trastocar sus vidas: irónica y precisamente lo que muchos adultos quieren evitar. Además, el hecho de que los mensajes de prevención a la salud provengan del mundo adulto, puede traer riesgos en cuanto a que se identifiquen con un mundo autoritario, que quiere imponer su voluntad sobre el deseo y anhelo de independencia de los chavos. Esta contingencia parece estarse experimentando en países primermundistas y avanzados en la educación de la sexualidad de los adolescentes y jóvenes, como Dinamarca, en donde los jóvenes hartos de la información sobre la prevención sexual que les dan desde los primeros años de la escuela 
primaria, hasta la etapa equivalente a la preparatoria, prefieren dejar de usar los métodos anticonceptivos en una especie de rebeldía a esta saturación e imposición del mundo adulto sobre sus conductas sexuales (M. Lisa Nielsen, comunicación personal, 16 de febrero de 2001).

Hoy en día existe la posibilidad de que las actuales generaciones de jóvenes vean los temas de la sexualidad más allá de las fronteras ideológicas de los diversos grupos sociales. Es decir, no se trata de imponer una u otra verdad en ellos, sino enseñarles a mirar las diversas realidades para que ellos decidan qué criterio quieren tomar y vivir. Los cambios, pequeños pero significativos que algunos adolescentes evidencian, permiten pensar que si bien la influencia de las religiones cristianas sigue presente en la sociedad potosina, existen puntos de quiebre que comienzan a revelar que nuevos vientos están soplando. La investigación por lo pronto da cuenta que el proceso de percepción de los adolescentes va más allá del consumo de los medios, y que sus ámbitos de aprendizaje y socialización los rebasan. Las campañas deben tener en cuenta esto, y entender que el público meta no sólo consta de jóvenes, sino principalmente de adultos, y en específico los padres. Los programas de prevención a la salud, para un mejor funcionamiento, deben de trabajar estos últimos, buscando convivir con las diversas concepciones y normas que existen respecto a la sexualidad, sobre todo a la adolescente, pero tratando de abogar al mismo tiempo por reglas sociales que protejan la salud de los jóvenes. Así, el esfuerzo no debe ser de los medios solamente, sino del conjunto social. Y si bien hay una disparidad entre la formación y educación de los padres, mediada también por las clases sociales, los programas deben buscar la forma de agregarlos en la dinámica de cambio. Pensar que es difícil que los adultos cambien, implica colocar un obstáculo de antemano que de una u otra manera afecta a los adolescentes. De manera semejante, pensar que si las campañas se enfocan a las nuevas generaciones porque al crecer cambiarán sus hábitos y disposiciones, se convierte en una falacia, pues descontextualizan al joven de su entorno y circunstancias socioculturales e históricas, pensándolo como un ser asocial.

Por lo demás, la pantalla chica presenta una gran posibilidad en vez de una gran desventaja, es decir, la televisión se convierte en la opción real y concreta de difundir contenidos que promocionen la salud en todo su espectro $y$, hoy en tiempos de sida y drogas, promover conductas preventivas -sean desde la abstinencia sexual hasta el sexo seguro- sin tener que provocar discordancias entre los diversos grupos 
sociales; o promocionar una campaña más agresiva en la que verdaderamente se logre mostrar lo que son las drogas y sus efectos, en circunstancias específicas en las que los adolescentes viven y se mueven. Las ideologías particulares de los grupos sociales no deben prevalecer sobre las realidades de los jóvenes. Vale más la vida de un joven, es decir, el uso de un condón si hablamos de sida, sexualidad y protección, que preservar un valor particular llámese pecado, inmoralidad, etc.

\section{Referencias Bibliográficas}

Chávez M., M. G. (2001). De cuerpo entero... Todo por hablar de música. Tesis de Doctorado. México: Universidad de Colima.

Chiu Amparán, A. (Coord.) (2002). Sociología de la identidad. México: UAM - Iztapalapa.

Esteinou Madrid, J. (1997). Medios de comunicación y transformación de la familia. En J. C. Lozano y C. Benassini (edit.), Anuario de la Investigación de la Comunicación, Coneicc IV. México: Coneicc/UdG.

Feixa Pàmpols, C. (1986). De jóvenes, bandas y tribus. Antropología de la juventud. España, Editorial Ariel.

Galindo C., J. (1992). Ideología y Comunicación. El Estado, la Hegemonía y la Difusión Masiva. México: Premia.

García Canclini, N. (2003). Culturas urbanas de fin de siglo: la mirada antropológica. Disponible en http:// www.cholonautas.edu.pe/pdf/CULTURAS\%URBANASGARCIA\%20CANCLINI.pdf

Jiménez, G. (2002). Paradigmas de identidad. En A. Chihu Amparán (Coord.), Sociología de la identidad. México: UAM Iztapalapa.

Moore, S., Rosenthal, D y Mitchel, A. (1996). Youth, AIDS and sexually transmitted diseases. London-USA-Canada: Routledge.

Orozco, G. (1995). Desafíos pedagógicos de la formación profesional del comunicador: comunicación, modernización y democracia. En J. Galindo y C. Luna (Coord.). Campo académico de la comunicación: hacia una reconstrucción reflexiva. México: ITESO/CONACULTA.

Passerini, L. (1996). La juventud, metáfora del cambio social (dos debates sobre los jóvenes en la Italia fascista y en los Estados Unidos durante los años cincuenta). En G. Levi y J. C. Schmitt 
(coord.), Historia de los jóvenes. II. La edad contemporânea. España: Santillana/Taurus.

Reguillo, R. (2003) Identidades culturales y espacio público: un mapa de los silencios. Diálogos de la Comunicación [Versión electrónica] (59-60). Disponible en http://www.felafacs.org/ dialogos/59-60/.Reguillo.pdf. (1995) Pensar la ciudad desde la comunicación. Un ejercicio necesario. En J. Galindo, y C. Luna (Coord.), Campo académico de la comunicación: hacia una reconstrucción reflexiva. México: ITESO/CONACULTA. (2000). Emergencia de culturas juveniles. Estrategias del desencanto. Enciclopedia Latinoamericana de Sociocultura y Comunicación. Argentina: Editorial Norma.

Sartori, G. (1997) Homo videns. La sociedad teledirigida. España: Taurus. 